PREPARED FOR THE U.S. DEPARTMENT OF ENERGY, UNDER CONTRACT DE-AC02-76CH03073

PPPL-3779

PPPL-3779

UC-70

\author{
Unified Ideal Stability Limits \\ for Advanced Tokamak and Spherical Torus Plasmas
}

by

J.E. Menard, M.G. Bell, R.E. Bell, D.A. Gates, S.M. Kaye, B.P. LeBlanc,

S.A. Sabbagh, E.D. Fredrickson, S.C. Jardin, R. Maingi, J. Manickam,

D. Mueller, M. Ono, F. Paoletti, Y.-K.M. Peng, V. Soukhanovskii,

D. Stutman, E.J. Synakowski, and the NSTX research team

February 2003

NM|

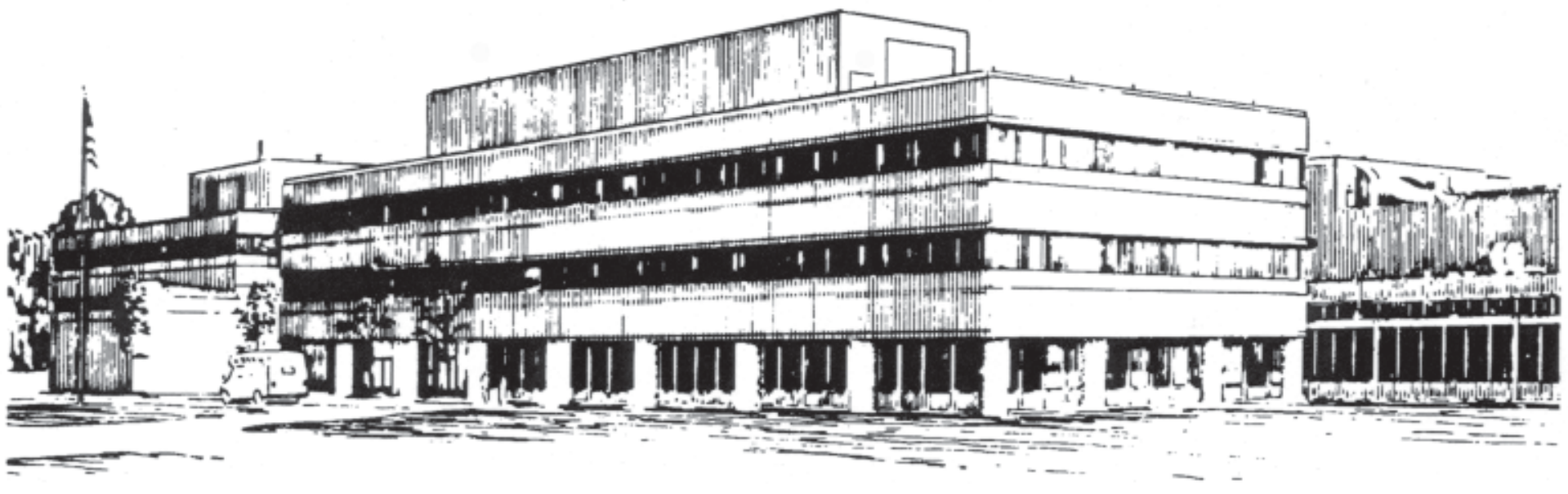

PRINCETON PLASMA PHYSICS LABORATORY PRINCETON UNIVERSITY, PRINCETON, NEW JERSEY 


\section{PPPL Reports Disclaimer}

This report was prepared as an account of work sponsored by an agency of the United States Government. Neither the United States Government nor any agency thereof, nor any of their employees, makes any warranty, express or implied, or assumes any legal liability or responsibility for the accuracy, completeness, or usefulness of any information, apparatus, product, or process disclosed, or represents that its use would not infringe privately owned rights. Reference herein to any specific commercial product, process, or service by trade name, trademark, manufacturer, or otherwise, does not necessarily constitute or imply its endorsement, recommendation, or favoring by the United States Government or any agency thereof. The views and opinions of authors expressed herein do not necessarily state or reflect those of the United States Government or any agency thereof.

\section{Availability}

This report is posted on the U.S. Department of Energy's Princeton Plasma Physics Laboratory Publications and Reports web site in Fiscal Year 2003. The home page for PPPL Reports and Publications is: http://www.pppl.gov/pub_report/

DOE and DOE Contractors can obtain copies of this report from:

U.S. Department of Energy

Office of Scientific and Technical Information

DOE Technical Information Services (DTIS)

P.O. Box 62

Oak Ridge, TN 37831

Telephone: (865) 576-8401

Fax: (865) 576-5728

Email: reports@adonis.osti.gov

This report is available to the general public from:

National Technical Information Service

U.S. Department of Commerce

5285 Port Royal Road

Springfield, VA 22161

Telephone: $1-800-553-6847$ or

(703) $605-6000$

Fax: (703) 321-8547

Internet: http://www.ntis.gov/ordering.htm 


\title{
Unified Ideal Stability Limits for Advanced Tokamak and Spherical Torus Plasmas
}

\author{
J.E. Menard ${ }^{1}$, M.G. Bell ${ }^{1}$, R.E. Bell ${ }^{1}$, D.A. Gates ${ }^{1}$, S.M. Kaye ${ }^{1}$, B.P. LeBlanc ${ }^{1}$, S.A. Sabbagh ${ }^{2}$, \\ E.D. Fredrickson ${ }^{1}$, S.C. Jardin ${ }^{1}$, R. Maingi ${ }^{3}$, J. Manickam ${ }^{1}$, D. Mueller ${ }^{1}$, M. Ono ${ }^{1}$, F. Paoletti ${ }^{2}$, \\ Y.-K.M. Peng ${ }^{3}$, V. Soukhanovskii ${ }^{1}$, D. Stutman ${ }^{4}$, E.J. Synakowski ${ }^{1}$, and the NSTX research team. \\ ${ }^{1}$ Princeton Plasma Physics Laboratory, Princeton, New Jersey \\ ${ }^{2}$ Columbia University, New York, New York \\ ${ }^{3}$ Oak Ridge National Laboratory, Oak Ridge, Tennessee \\ ${ }^{4}$ Johns Hopkins University, Baltimore, Maryland
}

(Dated: September 6, 2002)

\begin{abstract}
Ideal magnetohydrodynamic stability limits of shaped tokamak plasmas with high bootstrap fraction are systematically determined as a function of plasma aspect ratio. For plasmas with and without wall stabilization of external kink modes, the computed limits are well described by distinct and nearly invariant values of a normalized beta parameter utilizing the total magnetic field energy density inside the plasma. Stability limit data from the low aspect ratio National Spherical Torus Experiment is compared to these theoretical limits and indicates that ideal non-rotating plasma no-wall beta limits have been exceeded in regimes with sufficiently high cylindrical safety factor. These results could impact the choice of aspect ratio in future fusion power plants.
\end{abstract}

PACS numbers: 52.55.Fa, 28.52.Av

Introduction - The superconducting advanced tokamak $[1,2]$ is presently the leading candidate for producing an efficient magnetic fusion reactor. Alternative concepts such as the compact stellarator $[3,4]$ and spherical torus [5-7] are also actively being pursued as possible improvements to the advanced tokamak. The advanced tokamak (AT) and spherical torus (ST) reactor concepts have several features in common. In particular, both rely on the neoclassical bootstrap current [8] to sustain nearly all of the plasma current and on stabilization of pressure-driven external kink modes to achieve sufficiently high beta (ratio of plasma kinetic pressure to magnetic pressure) to produce power efficiently. The AT and ST reactor concepts have been independently optimized for various physics and engineering constraints and arrive at notably different plasma aspect ratio and beta. This difference has motivated the present work which seeks to understand how the theoretical ideal magnetohydrodynamic (MHD) stability limits of the AT and ST are linked. More generally, aspect ratio invariants of stability are sought.

The first equilibrium regime studied consists of fully self-driven plasmas utilizing a close-fitting conducting wall to stabilize external kink modes. The stability limits of this regime represent the maximum achievable beta for this class of equilibrium at any aspect ratio given the present understanding of the relevant physics. The second regime studied consists of plasmas with a self-driven current fraction of $50 \%$ and no conducting wall stabilization of the external kink mode. The stability limits of this regime have largely been experimentally realized in present-day tokamaks [9] but have only recently been realized in relatively new ST experiments. Finally, the no-wall current limit is studied for typical AT and ST configurations. These studies show that the degeneracy in possible definitions of normalized beta $[10,11]$ can be removed at low aspect ratio, and it is found that a normalized beta parameter utilizing the total magnetic field energy density inside the plasma unifies stability limits across plasma aspect ratio. Using these theoretical results, it is further shown that strongly heated National Spherical Torus Experiment (NSTX) [12] plasmas have reached and in some operating regimes significantly exceeded profile-optimized ideal stability limits computed in the absence of plasma rotation and wall stabilization.

Fully self-sustained with-wall stability - The numerical methods and definitions used here for determining equilibrium and stability are well established and have been described previously [13]. To compute the highest achievable beta limit for wall-stabilized self-sustaining plasmas, several assumptions are made. The plasma boundary is assumed to be limited and D-shaped with a triangularity $\delta=0.6-0.65$. The self-driven current fraction is held at or above $99 \%$. The $\mathrm{n}=0$ vertical instability and kink modes with toroidal mode number below 9 are stabilized by a superconducting conformal wall positioned no closer than $10 \%$ of the plasma minor radius away from the plasma surface. All equilibria treated are marginally stable to high-n ballooning modes and are constrained to have zero pressure gradient and current density at the plasma boundary to avoid edge-localized kink-ballooning modes. Finally, the density and temperature profile functions are chosen to have similar peaking factors, and $Z_{\text {ave }}=1.25$ and $Z_{\text {eff }}=2$ are assumed in the specification of the collision-less bootstrap current density profile.

Figure 1 shows the profile-optimized maximum stable beta and elongation for wall-stabilized self-sustained plasmas. As seen in Figure 1a, the toroidal beta $\beta_{t} \equiv$ $2 \mu_{0}\langle\mathrm{p}\rangle / \mathrm{B}_{\mathrm{t} 0}{ }^{2}$ increases nearly an order of magnitude from 


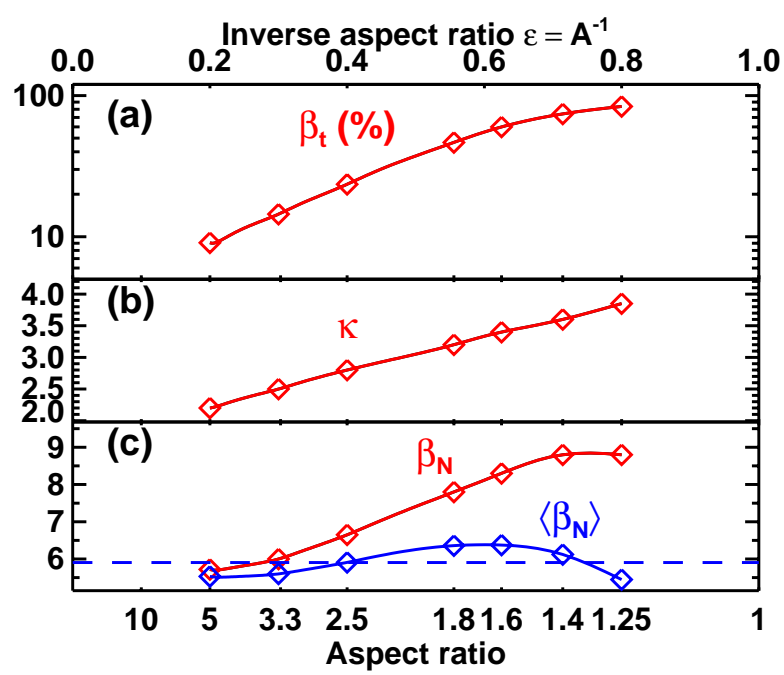

FIG. 1: (a) Toroidal beta, (b) plasma elongation, and (c) normalized beta values versus aspect ratio for wall-stabilized fully self-sustained equilibria.

$9 \%$ to $84 \%$ as the aspect ratio $\mathrm{A}$ is decreased from 5 to 1.25 . Figure $1 \mathrm{~b}$ shows that the elongation $\kappa$ nearly doubles from 2.2 to 3.9 for the same range of aspect ratios. For elongations above those shown in Figure $1 \mathrm{~b}, \beta_{t}$ cannot be further increased without destabilizing low-n kink modes with a conformal conducting wall at $r_{\text {wall }} / a=1.1$. Figure 1c shows that the normalized toroidal beta $\beta_{N} \equiv$ $\beta_{\mathrm{t}}(\%) \mathrm{aB}_{\mathrm{t} 0} / \mathrm{I}_{\mathrm{P}}(\mathrm{MA})$ increases from 5.7 to 9.0 . It can be shown [13] that $\beta_{t} \sim A^{-1 / 2}\left(1+\kappa^{2}\right) \beta_{N}^{2} / f_{B S}$, implying that the explicit dependence of the beta limit on aspect ratio is relatively weak when the bootstrap current fraction $f_{B S}$ is held fixed. Thus, the strong dependence of the elongation and normalized toroidal beta on aspect ratio are together responsible for most of the increase in toroidal beta with decreasing aspect ratio. Figure 1c also shows that the normalized volume-averaged beta $\left\langle\beta_{N}\right\rangle \equiv$ $\langle\beta\rangle(\%) \mathrm{aB}_{\mathrm{to}} / \mathrm{I}_{\mathrm{P}}(\mathrm{MA})$ where $\langle\beta\rangle \equiv 2 \mu_{0}\langle\mathrm{p}\rangle /\left\langle\mathrm{B}^{2}\right\rangle[11]$ exhibits much smaller variation with aspect ratio than $\beta_{N}$ and is an approximate stability invariant. These results suggest that the beta limit for wall-stabilized selfsustaining configurations is $\left\langle\beta_{N}\right\rangle \approx 6$ nearly independent of aspect ratio.

The optimal profiles in the stability calculations discussed above are found to vary only slightly with aspect ratio with one notable exception. Figure 2a shows that the safety factor profile for $A=1.6$ is monotonically increasing as a function of minor radius (square root of the normalized poloidal flux), while for $\mathrm{A}=3.3$ the q profile exhibits strongly reversed-shear. The shear changes sign from positive to negative near $\mathrm{A}=2.0$, so this aspect ratio represents a possible natural dividing line between the spherical torus and advanced tokamak. Figure $2 \mathrm{~b}$ shows that the optimal pressure profiles are generally quite broad, and the pressure peaking factors $\mathrm{p}(0) /\langle\mathrm{p}\rangle$ are found to increase from 1.38 to 1.57 between $\mathrm{A}=1.25$ and $A=5.0$. Figure 2c shows that both current density
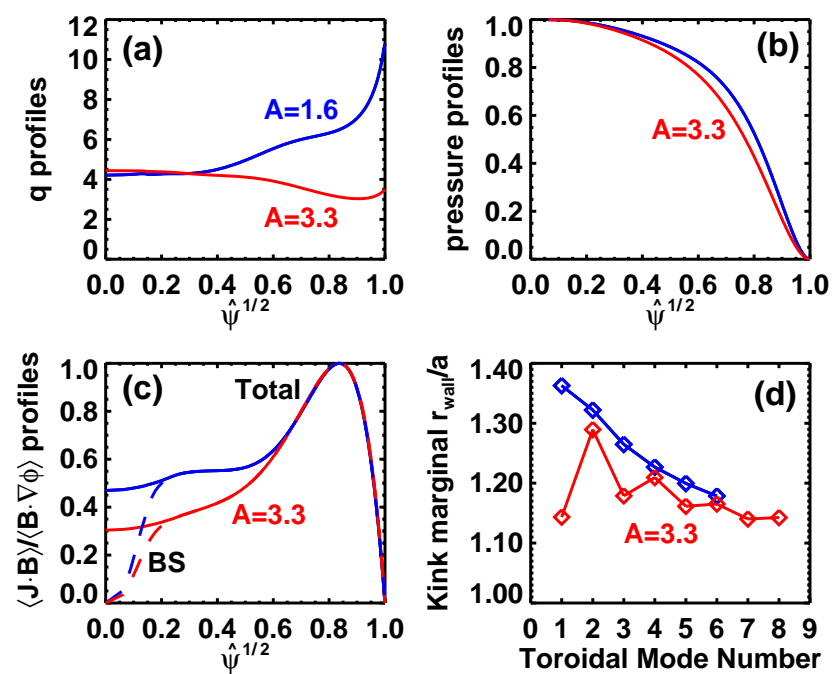

FIG. 2: (a) q (safety factor) profiles, (b) normalized pressure profiles, (c) normalized current density profiles, and (d) kink marginally-stable wall position divided by plasma minor radius for the $\mathrm{A}=1.6$ and $\mathrm{A}=3.3$ equilibria shown in Figure 1.

profiles are hollow and driven completely by the bootstrap effect except for a small region in the core. Finally, as shown in Figure 2d, for low aspect ratio there is a monotonic decrease in marginal wall position with increasing toroidal mode number. In contrast, for high aspect ratio the wall position can exhibit oscillations due the influence of individual mode rational surfaces associated with lower edge safety factor and shear.

Partially self-sustained no-wall stability - The fully self-driven regimes with very high beta and elongation outlined above are theoretically achievable but have not yet been realized experimentally. Elongation values in excess of those shown in Figure 1b have recently been achieved for $A=3.5$ [14], but not yet at high beta. The physical understanding of external kink stabilization utilizing rotation [15, 16] and active feedback [17] has improved significantly recently, but normalized beta values significantly above those attainable with optimized profiles without conducting wall stabilization are not easily achieved. Further, the pressure profile control techniques required to realize the highest beta values in fully bootstrapped regimes are only beginning to be developed. These factors motivate an investigation of the aspect ratio dependence of the ideal beta limit for parameters more typical of present-day experiments.

In the following analysis, ideal beta limits are determined for equilibria with a fixed self-driven current fraction of $50 \%$ (with no local bootstrap current overdrive) and which are marginally stable to ballooning modes and $\mathrm{n}=1-3$ kink modes without wall stabilization. For most aspect ratios treated, the optimization of the pressure and current profiles results in the equilibrium being simultaneously marginally stable to ballooning and $n=1$ kink modes. With this set of constraints and with a fixed plasma boundary shape with elongation $\kappa=2.0$ and tri- 


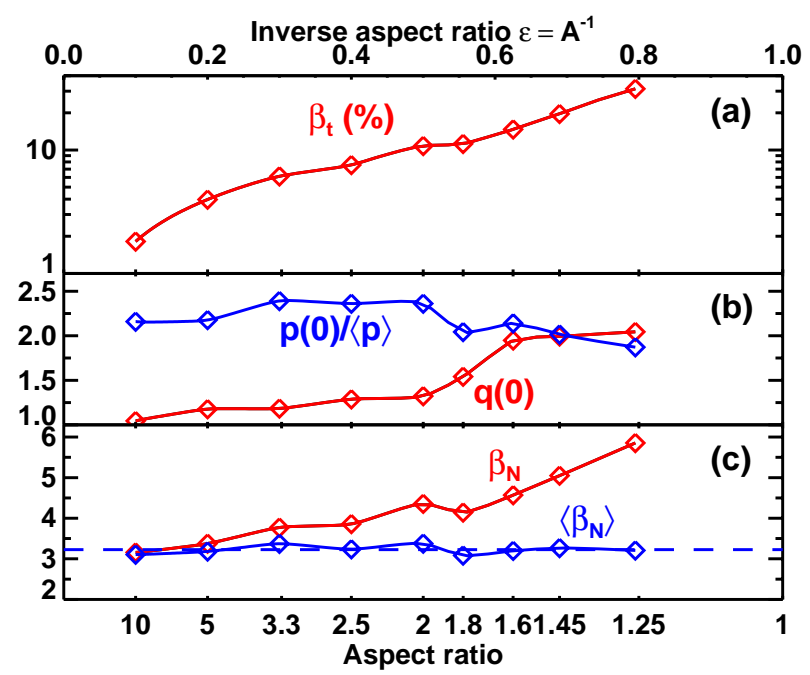

FIG. 3: (a) Toroidal beta, (b) pressure peaking and central safety factor, and (c) normalized toroidal and volume average beta values versus aspect ratio for the $50 \%$ self-sustained configuration not utilizing wall stabilization.

angularity $\delta=0.45$, Figure 3a again shows an order of magnitude increase in toroidal beta as the aspect ratio is decreased from 10 to 1.25 . Figure $3 \mathrm{~b}$ shows that the optimal pressure peaking is significantly higher when wall stabilization cannot be utilized and that there is a systematic decrease in the optimal peaking for $\mathrm{A}<2$. This figure also shows that the optimal central safety factor is approximately 2 for $\mathrm{A}<1.6$ and 1 to 1.3 for $\mathrm{A}>2$. Thus, for this optimization, $\mathrm{A}=1.8$ is apparently a transitional aspect ratio lying between the spherical torus and tokamak. Finally, Figure 3c shows that the normalized toroidal beta increases from 3.15 to 5.85 between $\mathrm{A}=10$ and 1.25. In contrast, the normalized volume-averaged beta is again essentially independent of aspect ratio with a standard deviation of only $3 \%$ and mean value of 3.2 .

To further test the near aspect ratio invariance of $\left\langle\beta_{N}\right\rangle$ discussed above, additional no-wall stability scans with varied plasma shape and self-driven current fraction have been performed. Figure $4 \mathrm{a}$ shows that at $\mathrm{A}=1.6$ with fixed self-driven current fraction of $50 \%$, the no-wall kink and ballooning marginally stable toroidal beta can vary as much as a factor of 4 depending on shaping. For these shape changes, Figure 4b shows that the normalized toroidal beta varies from 3.4 to 5 , while the normalized volume-average beta values have only a $5 \%$ deviation from a mean value of 3.0 with the exception of the case with the lowest triangularity and highest elongation. Figure $4 \mathrm{c}$ plots $\langle\beta\rangle$ versus $\mathrm{I}_{\mathrm{P}} / \mathrm{aB}_{\mathrm{t} 0}$ for the aspect ratio scan of Figure 3 (crosses), the shape scan of Figure 4a (triangles), and $\mathrm{I}_{\mathrm{P}}$ scans with self-driven current fraction ranging from 0 to 0.6 for $\mathrm{A}=1.6, \kappa=2, \delta=0.45$ (squares), $\mathrm{A}=1.6, \kappa=2.5, \delta=0.6$ (circles), and $\mathrm{A}=3.3$, $\kappa=2, \delta=0.45$ (diamonds). As seen in the figure, the solid line of $\langle\beta\rangle(\%)=3.2 \mathrm{I}_{\mathrm{P}} / \mathrm{aB}_{\mathrm{t} 0}(\mathrm{MA} / \mathrm{mT})$ represents a good fit to the upper bound of the computed beta lim-
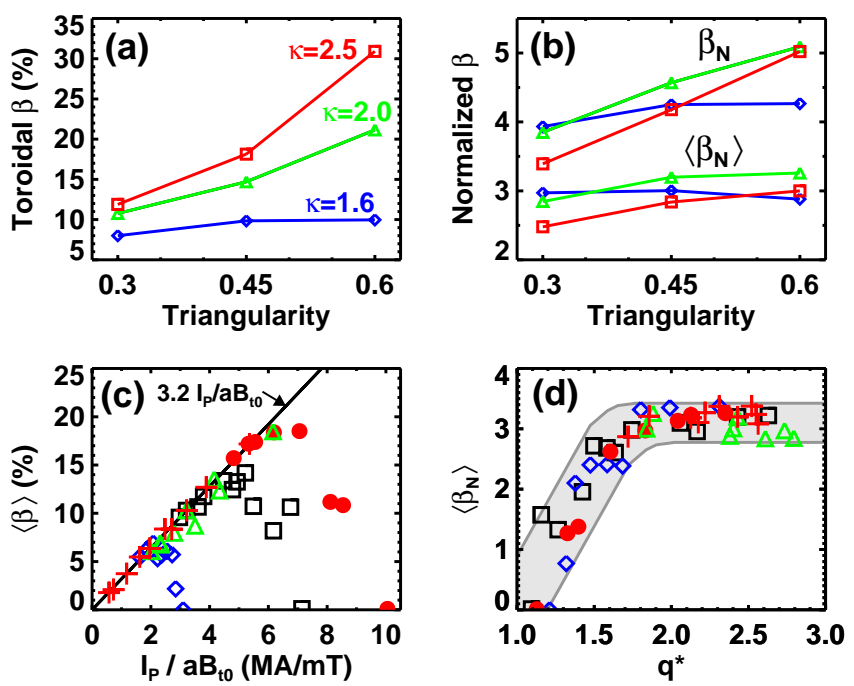

FIG. 4: (a) Marginally stable $\beta_{t}(\%)$ and (b) normalized beta values as a function of triangularity and elongation at $50 \%$ self-driven current fraction for aspect ratio $A=1.6$. (c) $\langle\beta\rangle$ versus $\mathrm{I}_{\mathrm{P}} / \mathrm{aB}_{\mathrm{t} 0}$ and $(\mathrm{d})\left\langle\beta_{N}\right\rangle$ versus cylindrical safety factor for the aspect ratio, shape, and $\mathrm{I}_{\mathrm{P}}$ scans performed.

its. For cases with $\left\langle\beta_{N}\right\rangle$ significantly below 3 , it is found that $\left\langle\beta_{N}\right\rangle$ degrades rapidly as the cylindrical safety factor $q^{*} \equiv \epsilon\left(1+\kappa^{2}\right) \pi \mathrm{aB}_{\mathrm{t} 0} / \mu_{0} \mathrm{I}_{\mathrm{P}}[13,18]$ is decreased below 1.7 for both $\mathrm{A}=1.6$ and $\mathrm{A}=3.3$, as shown in Figure $4 \mathrm{~d}$. This figure suggests that $\left\langle\beta_{N}\right\rangle$ and $q^{*}$ are parameters well suited for describing the dependence of the profileoptimized no-wall stability limit on safety factor across plasma aspect ratio. This finding extends early analytic treatments of the tokamak current limit [18] to more realistic profiles and appears to be consistent with experimental stability data $[19,20]$ at high normalized current $\mathrm{I}_{\mathrm{P}} / \mathrm{aB}_{\mathrm{t} 0}$ from standard aspect ratio tokamaks.

NSTX stability and implications - Recent machine improvements in the NSTX device now allow routine access to the H-mode [21] and its associated low pressure profile peaking $(p(0) /\langle p\rangle \approx 1.8-2.5)$ predicted to be optimal for ideal MHD stability in the ST [13, 22]. Figure 5a plots peak NSTX beta values computed with the EFIT equilibrium reconstruction code [23] for plasmas with shape parameters spanning $\mathrm{A}=1.27-1.5, \kappa=1.5-2.15, \delta=0.25-0.85$ and internal inductance $l_{i}=0.5-1.7$. As seen in the figure, peak beta values have reached $\beta_{t} \geq 30 \%$ with $\beta_{N} \geq 6$ and $\left\langle\beta_{N}\right\rangle>3$ surpassing previous ST record normalized beta values from the START experiment [24]. Further, NSTX experimental $\left\langle\beta_{N}\right\rangle$ values plotted versus $q^{*}$ in Figure $5 \mathrm{~b}$ exhibit the predicted current-limit behavior at low $q^{*}$ shown by the shaded region from Figure $4 \mathrm{~d}$.

Importantly, $\mathrm{H}$-mode discharges with $\mathrm{A}=1.4-1.5, \kappa \approx$ $2, \delta \approx 0.4$, and $l_{i}=0.6-0.95$ optimized to have very long ELM-free and sawtooth-free periods and $q^{*}$ in the range of 2.5-3.0 have exceeded the theoretical no-wall limit by as much as $30 \%$ as seen in Figure 5 b. Figure 6 shows that this high $\left\langle\beta_{N}\right\rangle \geq 4$ state can be sustained for several energy confinement times $\left(\tau_{E}=40-50 \mathrm{~ms}\right)$ and 

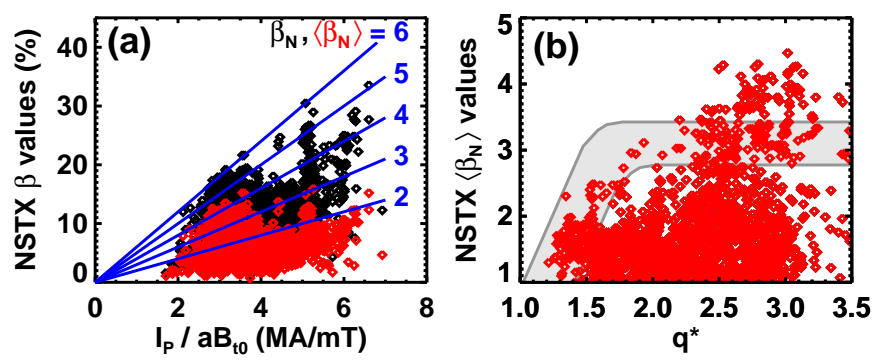

FIG. 5: (a) $\beta_{t}$ (black) and $\langle\beta\rangle$ (red) at maximum stored energy for NSTX NBI-heated discharges plotted versus normalized current. Constant normalized beta lines are shown in blue. (b) $\left\langle\beta_{N}\right\rangle$ versus $q^{*}$ for the discharges from (a).

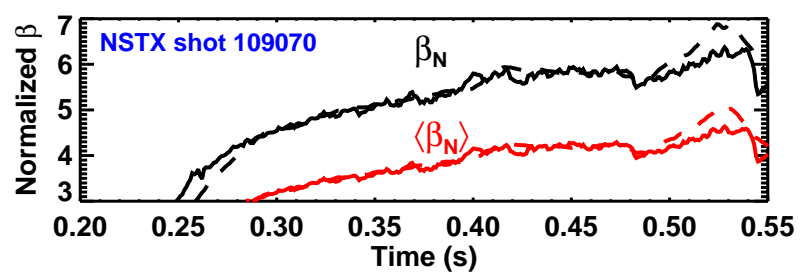

FIG. 6: Time history of a high $\left\langle\beta_{N}\right\rangle$ discharge from Figure $5 \mathrm{~b}$ as computed by EFIT (solid) and TRANSP (dashed).

many resistive wall times $\left(\tau_{\text {wall }}=5-15 \mathrm{~ms}\right)$ and that there is excellent agreement between partial-kinetic EFIT reconstructions [25] and full kinetic calculations using the measured $n_{e}, T_{e}$, and $T_{i}$ profiles, line-average $Z_{\text {eff }}$, and fast ion pressure computed with the TRANSP [26] code. Wall-stabilization of the pressure-driven kink mode from the close fitting conducting plates and beam driven rotation in NSTX [25] is a likely explanation of the violation of the no-wall limit shown in Figures 5b and 6, although shear stabilization of either kink or ballooning modes [27] may also play a role. These discharges also reach poloidal beta values above 1.2 (several are measured to be slightly diamagnetic) with weak $n=1-3$ mode activity present but do not appear to be limited by $n=1$ tearing modes as observed in MAST [28]. EFIT reconstructions yield $q(0) \gg$ 1 for some of these discharges, but confirmation of elevated $q$ awaits internal q profile measurements in NSTX.

Given the ability of NSTX plasmas to reach and in some cases exceed ideal profile-optimized no-wall stability limits, the results shown in Figures 1 and 3 for low aspect ratio can be used with increased confidence in future design studies. Recent studies [29] utilizing stability parameterizations based on a more limited range of aspect ratio and bootstrap fraction than treated here have already shown that increases in $\beta_{N}$ and $\kappa$ with decreasing aspect ratio can lead to device optimization at significantly lower aspect ratio than otherwise achieved.

Summary - Systematic ideal stability calculations for tokamak and spherical torus configurations scanning plasma aspect ratio, shape, and safety factor have been performed. The volume-averaged normalized beta parameter is found to best unify calculated stability limits across plasma aspect ratio. The computed limits are $\left\langle\beta_{N}\right\rangle=6 \pm 0.4$ for the wall-stabilized fully self-sustained configuration and $\left\langle\beta_{N}\right\rangle=3.1 \pm 0.3$ without wall stabiliza- tion for $q^{*}$ above 1.7. Below this value of $q^{*}$, the no-wall $\left\langle\beta_{N}\right\rangle$ limit decreases rapidly as the current limit threshold of $q^{*} \approx 1$ is approached. NSTX peak $\left\langle\beta_{N}\right\rangle$ values are at or below the profile-optimized no-wall limit for low $q^{*} \leq 2$, but have significantly surpassed this limit for $q^{*}>2$ in some operating scenarios. The role of the pressure and current profile shape, wall stabilization, and rotation and rotational shear in allowing operation above the profile-optimized no-wall ideal stability limit in NSTX will be studied in more detail in future work.

This research was supported by the United States Department of Energy under contract numbers DE-AC0276CH03037 (PPPL), DE-AC05-00R22725 (ORNL), and grant numbers DE-FG02-99ER54524 (CU), DE-FG0299ER54523 (JHU).

[1] S. Jardin et al., Fus. Engin. and Design 38, 27 (1997).

[2] C. Kessel, T. Mau, S. Jardin, and F. Najmabadi, Technical Report No. PPPL-3573, Princeton Plasma Physics Laboratory, (unpublished), submitted for publication to Fus. Eng. Design.

[3] S. Hirshman et al., Phys. Rev. Lett. 80, 528 (1998).

[4] M. C. Zarnstorff et al., Plasma Phys. and Contr. Fus. 43, 237 (2001).

[5] Y.-K. M. Peng and D. J. Strickler, Nucl. Fus. 26, 769 (1986).

[6] R. D. Stambaugh, V. S. Chan, R. L. Miller, and M. J. Schaffer, Fus. Technol. 33, 1 (1998).

[7] S. C. Jardin et al., Fus. Engin. and Design to be published (2002).

[8] R. J. Bickerton, J. W. Connor, and J. B. Taylor, Nature Phys. Sci. 229, 110 (1971).

[9] M. R. Wade et al., Phys. Plasmas 8, 2208 (2001).

[10] A. Sykes, M. Turner, and S. Patel, in Proceedings of the 11th European Conference on Controlled Fusion and Plasma Physics, Aachen, Germany, 1983, European Physical Society, edited by S. Methfessel (Petit-Lancy, Switzerland, 1983), Vol. 7D, Part II, p. 363.

[11] F. Troyon et al., Plasma Phys. and Contr. Fus. 26, 209 (1984).

[12] M. Ono et al., Nucl. Fus. 40, 557 (2000).

[13] J. E. Menard et al., Nucl. Fus. 37, 595 (1997).

[14] F. Hofmann et al., Nucl. Fus. 42, 743 (2002).

[15] A. Bondeson and D. J. Ward, Phys. Rev. Lett. 72, 2709 (1994).

[16] A. M. Garofalo et al., Phys. Rev. Lett. 82, 3811 (1999).

[17] Y. Q. Liu and A. Bondeson, Phys. Rev. Lett. 84, 907 (2000).

[18] D. A. D'Ippolito, J. P. Freidberg, J. P. Goedbloed, and J. Ram, Phys. Fluids 21, 1600 (1978).

[19] E. Strait, Phys. Plasmas 1, 1415 (1994).

[20] F. Hofmann et al., Phys. Rev. Lett. 81, 2918 (1998).

[21] R. Maingi et al., Phys. Rev. Lett. 88, 035003 (2002).

[22] F. Paoletti et al., Nucl. Fus. 42, 418 (2002).

[23] S. A. Sabbagh et al., Nucl. Fus. 41, 1601 (2001).

[24] M. Gryaznevich et al., Phys. Rev. Lett. 80, 3972 (1998).

[25] S. A. Sabbagh et al., Phys. Plasmas 9, 2085 (2002).

[26] R. J. Goldston, D. C. McCune, and H. H. Towner, J. Comput. Phys. 43, 61 (1981).

[27] F. Waelbroeck and L. Chen, Phys. Fluids B 3, 601 (1991).

[28] R. J. Buttery et al., Phys. Rev. Lett. 88, 125005 (2002).

[29] C. P. C. Wong et al., Nucl. Fus. 42, 547 (2002). 


\section{External Distribution}

Plasma Research Laboratory, Australian National University, Australia

Professor I.R. Jones, Flinders University, Australia

Professor João Canalle, Instituto de Fisica DEQ/IF - UERJ, Brazil

Mr. Gerson O. Ludwig, Instituto Nacional de Pesquisas, Brazil

Dr. P.H. Sakanaka, Instituto Fisica, Brazil

The Librarian, Culham Laboratory, England

Mrs. S.A. Hutchinson, JET Library, England

Professor M.N. Bussac, Ecole Polytechnique, France

Librarian, Max-Planck-Institut für Plasmaphysik, Germany

Jolan Moldvai, Reports Library, MTA KFKI-ATKI, Hungary

Dr. P. Kaw, Institute for Plasma Research, India

Ms. P.J. Pathak, Librarian, Insitute for Plasma Research, India

Ms. Clelia De Palo, Associazione EURATOM-ENEA, Italy

Dr. G. Grosso, Instituto di Fisica del Plasma, Italy

Librarian, Naka Fusion Research Establishment, JAERI, Japan

Library, Plasma Physics Laboratory, Kyoto University, Japan

Research Information Center, National Institute for Fusion Science, Japan

Dr. O. Mitarai, Kyushu Tokai University, Japan

Library, Academia Sinica, Institute of Plasma Physics, People's Republic of China

Shih-Tung Tsai, Institute of Physics, Chinese Academy of Sciences, People's Republic of China

Dr. S. Mirnov, TRINITI, Troitsk, Russian Federation, Russia

Dr. V.S. Strelkov, Kurchatov Institute, Russian Federation, Russia

Professor Peter Lukac, Katedra Fyziky Plazmy MFF UK, Mlynska dolina F-2, Komenskeho Univerzita, SK-842 15 Bratislava, Slovakia

Dr. G.S. Lee, Korea Basic Science Institute, South Korea

Institute for Plasma Research, University of Maryland, USA

Librarian, Fusion Energy Division, Oak Ridge National Laboratory, USA

Librarian, Institute of Fusion Studies, University of Texas, USA

Librarian, Magnetic Fusion Program, Lawrence Livermore National Laboratory, USA

Library, General Atomics, USA

Plasma Physics Group, Fusion Energy Research Program, University of California at San Diego, USA

Plasma Physics Library, Columbia University, USA

Alkesh Punjabi, Center for Fusion Research and Training, Hampton University, USA

Dr. W.M. Stacey, Fusion Research Center, Georgia Institute of Technology, USA

Dr. John Willis, U.S. Department of Energy, Office of Fusion Energy Sciences, USA

Mr. Paul H. Wright, Indianapolis, Indiana, USA 
The Princeton Plasma Physics Laboratory is operated by Princeton University under contract with the U.S. Department of Energy.

\author{
Information Services \\ Princeton Plasma Physics Laboratory \\ P.O. Box 451 \\ Princeton, NJ 08543
}

Phone: 609-243-2750

Fax: 609-243-2751

e-mail: pppl_info@pppl.gov

Internet Address: http://www.pppl.gov 